\title{
EFFECT OF ORGANOCLAY INCORPORATION ON THERMAL, PHYSICAL AND MORPHOLOGICAL PROPERTIES OF LLDPE NANOCOMPOSITES FOR ACTIVE FOOD PACKAGING APPLICATIONS.
}

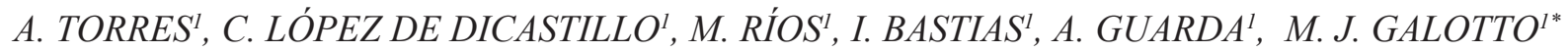 \\ ${ }^{1}$ Laboratory of Food Packaging (LABEN). University of Santiago de Chile (USACH). Technology Faculty. CEDENNA. Center for the Development of \\ Nanoscience and Nanotechnology.
}

\begin{abstract}
Active films based on nanocomposites from linear low-density polyethylene (LLDPE) were prepared by melting extrusion incorporating Cloisite $30 \mathrm{~B}$ (5 wt.\%) and thymol as active compound at two different concentrations: 2 and $4 \mathrm{wt} . \%$. A complete thermal, structural characterization and antioxidant capacity of all blends was carried out. Extraction procedures revealed final concentrations of thymol in the film between $40-80 \%$ of the thymol that was initially included in the films formulation. Materials with 2 and $4 \%$ of thymol presented similar antioxidant capacity. XRD results indicated a slightly lower degree of intercalation in the nanocomposites with thymol, due probably to the lower compatibility between the hydrophilic character of the clays, and the hydrophobic thymol substance. The addition of the antioxidant improved slightly the thermal stability of the polymer.
\end{abstract}

Keywords: linear low-density polyethylene, thymol, organoclay, antioxidant activity, nanocomposites

\section{INTRODUCTION}

Food packaging has the aim to protect food from environmental conditions, make distribution easier, and provide information and convenience to the consumer $^{1-3}$. Annually, plastics are produced about 250 million tons worldwide, which is the largest user of crude oil after energy and transportation, and more than $40 \%$ of the plastics are used for packaging ${ }^{4}$. Among the polyolefin plastics, $\mathrm{PE}$ is one of the most widely used due to its excellent processability, chemical inertness, safety in using for contact with food materials, good heat sealing property, and low production $\operatorname{cost}^{5}$. During the last few decades, consumer trends for better quality, fresh and convenience food products have intensified ${ }^{6}$.

Active packaging (AP) is an innovative food packaging concept that has been introduced and developed as a series of responses to the continuous changes in consumer demands and market trends ${ }^{7,8}$. The AP systems change the condition of the packaged food to extend the shelf life or to improve safety or sensory properties while maintaining the quality ${ }^{1,8,9}$. Some examples of AP systems include oxygen scavengers, moisture scavengers, ethylene scavengers, aroma emitters or absorbers and antioxidant or antimicrobial systems ${ }^{9-14}$. Different substances either natural or synthetic have been reported as potential antimicrobial or antioxidant additives, however, natural additives are preferred by consumers because they are perceived as low health risk compounds ${ }^{15}$. The increasing demand for natural additives has resulted in studies based on natural active compounds, such as plant extracts or essential oils (EOs), which are categorized as Generally Recognized as Safe (GRAS) by the US Food and Drug Administration as well as the current European Legislation for materials intended to be in contact with food (EU N10/2011 Regulation) ${ }^{16}$. Thymol is one the most abundant component of thyme and oregano EOs and it has received considerable attention do to their antioxidant capacity ${ }^{17-20}$. Clay minerals have also been of great interest in packaging because they can be used to obtain nanomaterials ${ }^{21}$. The development of different nanocomposites based on polyolefin with nanoclays and/or natural additives ${ }^{22-26}$ has been reported by several authors in the last years. Persico and coworkers ${ }^{24}$ studied the antimicrobial properties of nanocomposite films based on low-density polyethylene (LDPE) containing carvacrol and modified montmorillonite (MMT) was used as filler. In this case, the presence of clay and carvacrol increase LDPE crystallinity, while the mechanical properties of the films were slightly affected. However, few works have reported the combination of natural active additives and nanofillers in polymer matrices resulting in nanocomposites with antioxidant properties and functionalities for use in food packaging applications. Then, the aim of the present work was to evaluate the effect of commercial organoclay incorporation on thermal, physical and morphological properties of linear low-density polyethylene (LLDPE) nanocomposites for active-antioxidant food packaging applications.

\section{EXPERIMENTAL PROCEDURE}

Chemicals and reagents

LLDPE (MFI: $0.6 \mathrm{~g} / 10 \mathrm{~min}$ at $190^{\circ} \mathrm{C} / 2.16 \mathrm{~kg}, 926 \mathrm{kgm}^{-3}$ density) was supplied by Braskem, Brasil. The commercial organoclay Cloisite20A $(90 \mathrm{meq} / 100 \mathrm{~g})$ was provided by Southern Clay Products Methanol and thymol $(\geq 99.5 \%)$ were purchased from Sigma-Aldrich.

\section{Plastic films preparation}

LLDPE films with and without additives at different concentrations were obtained by flat extrusion. Cloisite 20A (C20A) was incorporated at a concentration of $5 \%(\mathrm{w} / \mathrm{w})$, and the active compound thymol at 2 and $4 \%$ $(\mathrm{w} / \mathrm{w})$. Blends 1-6 (see in Table 1) were obtained in a pilot scale extruder (Scientif LabTech LTE20 model) installed in the Laboratory of Food Packaging (LABEN) at University of Santiago de Chile. The temperature profile used was 130 to $150^{\circ} \mathrm{C}$ with a screw speed of $40 \mathrm{rpm}$ and a chill roll speed equal than 4.5rpm. Blank samples without organic clays are also extruded in order to study the effect of the nanoparticles presence in the polymeric matrix.

\section{Films characterization}

Quantification of thymol effective concentration

The effective thymol concentration in the LLDPE films after extrusion was determined through the method described by Quintero and coworkers ${ }^{27}$. Samples $(0.5 \mathrm{~g})$ were placed in $100 \mathrm{~mL}$ flasks filled with methanol. These flasks were sonicated in an ultrasound bath during $10 \mathrm{~min}$ at room temperature; methanol was recovered and filtered to be analyzed by means of a HPLC method.

Quantification of thymol was performed by an HPLC method carried out in an HPLC machine (Hitachi LaChrom Elite) equipped with a diode array detector (Hitachi L-2455) and autosampler (Hitachi L-2200). The chromatographic column used was a Chromolith FastGradient RP-18 endcapped 50-2 mm. The mobile phase consisted of a mixture of acetonitrile-distilled water (30:70 $\mathrm{v} / \mathrm{v})$ at a flow rate of $1 \mathrm{ml} \mathrm{min}-1$ and the injection volume was $5 \mu \mathrm{l}$. The oven temperature was constant at $40^{\circ} \mathrm{C}$. The detection of thymol was performed at $283 \mathrm{~nm}$. The calibration curve was constructed for peak area against the thymol concentration of standard solutions from 5 to $500 \mathrm{mgkg}^{-1}$ (ppm), with three samples for each thymol concentration. Thymol was identified by comparison of its retention time and UV spectra with those of an injected pure standard using the same HPLC conditions.

\section{Antioxidant activity}

Antioxidant capacity of the developed films was measured using DPPH method based on the sum of the radical scavenging activities of five consecutive extractions of each material obtained as explained in previous section. The DPPH method is based on the bleaching rate of a stable free radical, 2,2-diphenyl-1-picrylhydrazyl (DPPH·), monitored at a characteristic wavelength in the presence of the solutions. In its radical form DPPH absorbs at $517 \mathrm{~nm}$, but upon reduction by an antioxidant its absorption decreases. The percentage inhibition values were calculated using the equation 1 :

$$
\% \text { Inhibition }=\% \mathrm{I}=\left(\mathrm{A}_{\text {control }}-\mathrm{A}_{\text {sample }}\right) / \mathrm{A}_{\text {control }} * 100
$$


To standardize the results, scavenging activities of DPPH radicals were expressed as miligrams Trolox per gram of material, using a calibrated curve of Trolox concentration versus I (\%).

\section{Thermal Analysis}

Thermogravimetric analyses (TGA) were carried out using a TGA/ SDTA 851 Mettler Toledo thermal analyzer (Schwarzenbach, Switzerland) Samples (ca. $10 \mathrm{mg}$ ) were heated from 25 to $600^{\circ} \mathrm{C}$ at $10^{\circ} \mathrm{Cmin}^{-1}$ under nitrogen atmosphere (flow rate $50 \mathrm{mLmin}^{-1}$ ) in order to prevent any thermoxidative degradation.

Thermal properties of the materials were also determined with a Mettler Toledo DSC-822e calorimeter owing to analyze the effect of the interaction between organoclays and thymol on the morphology and crystallinity of the LDPE matrix. Thermograms were obtained from 25 to 250 with $10^{\circ} \mathrm{Cmin}^{-1}$ heating, cooling to $25^{\circ} \mathrm{C}$, and a second heating process to $250^{\circ} \mathrm{C}$. The sample weight was about 5-8 $\mathrm{mg}$. All experiments were carried out under the purge of dry nitrogen.

Melting temperature and enthalpy, $\mathrm{T}_{\mathrm{m}}$ and $\Delta \mathrm{H}_{\mathrm{m}}$, were calculated from the second heating process. The crystallinity $(\%)$ of the samples was estimated from the corrected enthalpy for the LLDPE content in the nanocomposites, using the ratio between the enthalpy of the studied materials and the enthalpy of a perfect LLDPE crystal. Considering the polymer percentage of each sample, a corrected enthalpy $(\Delta \mathrm{Hm}$,corr) value was also estimated.

Attenuated Total Reflectance Fourier Transform Infrared (ATRFTIR) spectroscopy.

Fourier transform infrared spectroscopy (FTIR) was used to characterize the presence of specific chemical groups in the materials. FTIR spectra of different films were recorded using a Bruker Alpha IFS 66V spectrometer equipped with an attenuated total reflexion diamond crystal accessory (Bruker, Platinium). The spectra were obtained with a resolution of $4 \mathrm{~cm}^{-1}$ in a wavenumber range from 4000 to $400 \mathrm{~cm}^{-1}$ with 24 scans. The spectra analysis was performed using OPUS Software Version 7.

\section{X-ray diffraction (XRD)}

Structures of nanoclays and LLDPE/clay/thymol nanocomposites films were evaluated with X-ray diffraction (XRD) measurements. XRD analysis were carried out in a Siemens Diffractometer D5000 (30 mA and $40 \mathrm{kV})$ using $\mathrm{CuKa}(\lambda=1.54 \AA)$ radiation at room temperature. All scans were performed in a $2 \theta$ range $2-12^{\circ}$ at $0.02^{\circ} / \mathrm{seg}$. Interlaminar distances were calculated using Bragg's Law:

$$
d=\lambda / 2 \sin \theta
$$

where $\lambda$ is the wavelength of the $\mathrm{X}$-ray radiation, $\mathrm{d}$ is the spacing between diffractional lattice planes $(\mathrm{nm})$ and $\theta$ is the measured diffraction angle $(\text { degree })^{28}$.

\section{Surface color measurement}

Films color was measured using a CR 410 Minolta Chroma Meter (Minolta Series, Tokyo, Japan) colorimeter. The film specimen was placed on the surface of a standard white place, and the CIELAB color space was used to determine the parameters lightness $\mathrm{L}$, and chromaticity parameters $\mathrm{a}$ (red-green) and b (yellow-blue). A white standard color plate was used as the background for color measurements D65 illuminant and $10^{\circ}$ observer was used for analysis. Each analysis was performed in five replicates and results reported the average value. Total color differences $(\Delta \mathrm{E})$, induced by thymol or organoclay incorporation, with respect to the control LLDPE film were evaluated using Equation 3 :

$$
\Delta E=\sqrt{a^{2}+b^{2}+L^{2}}
$$

Previously described experimental values of $\mathrm{L}^{*}, \mathrm{a}^{*}$ and $\mathrm{b}^{*}$ parameters were used to calculate the Whitish Index using the Equation (4):

$$
W i=100-\left[(100-L *)^{2}+a *^{2}+b *^{2}\right]^{1 / 2}
$$

Scanning electronic microscopy (SEM)

The SEM micrographs of nanocomposites films were obtained from a JSM-5410 Jeol Scanning Microscope with accelerating voltage at $10 \mathrm{kV}$.
Samples were coated with gold palladium using a Sputtering System Hummer 6.2. To the cross-section analysis, the samples were fractured using Tensile Tester.

\section{RESULTS AND DISCUSSION}

\section{Quantification of thymol effective concentration in LLDPE nanocomposites}

In this work, all formulations shown in Table 1 were successfully obtained by extrusion (70-90 $\mu \mathrm{m}$ thickness). The analysis of the methanol extracts of the different materials developed by HPLC chromatography revealed the final contents of thymol, being expressed in Table 1 as well. As Table 1 shows, after extrusion, extraction procedures revealed final concentrations of thymol in the film between $40-80 \%$ of thymol that was initially included in the films formulation.

Table 1: Composition of the different polyethylene-blends extruded.

\begin{tabular}{|c|l|c|c|c|c|c|}
\hline Blend & \multicolumn{1}{|c|}{ Sample } & LLDPE & Cloisite 20A & Thymol & Thymol t=0 & Thymol t=30days \\
\hline 1 & LLDPE & 1 & 0 & 0 & - & - \\
\hline 2 & LLDPE/C20A & 0.95 & 0.05 & 0 & - & - \\
\hline 3 & LLDPEThy2\% & 0.98 & 0 & 0.02 & $0.011(52 \%)$ & $0.0041(20.4 \%)$ \\
\hline 4 & LLDPE/Thy2\%/C20A & 0.93 & 0.05 & 0.02 & $0.014(68.5 \%)$ & $0.006(32.5 \%)$ \\
\hline 5 & LLDPE/Th4\% & 0.96 & 0 & 0.04 & $0.025(62.8 \%)$ & $0.0198(49.5 \%)$ \\
\hline 6 & LLDPE/Thy4\%/C20A & 0.91 & 0.05 & 0.04 & $0.02(49.1 \%)$ & $0.013(29.4 \%)$ \\
\hline
\end{tabular}

* LLDPE, Cloisite 20A and thymol are expressed on (w/w)

Several studies showed similar or higher losses of some volatile active agents due to stress and high temperature conditions during extrusion process $^{29,30}$. Concentration of thymol in the films over time (Figure 1) was also measured owing to quantify their activity during storage time, and maybe to estimate these films' shelf life.

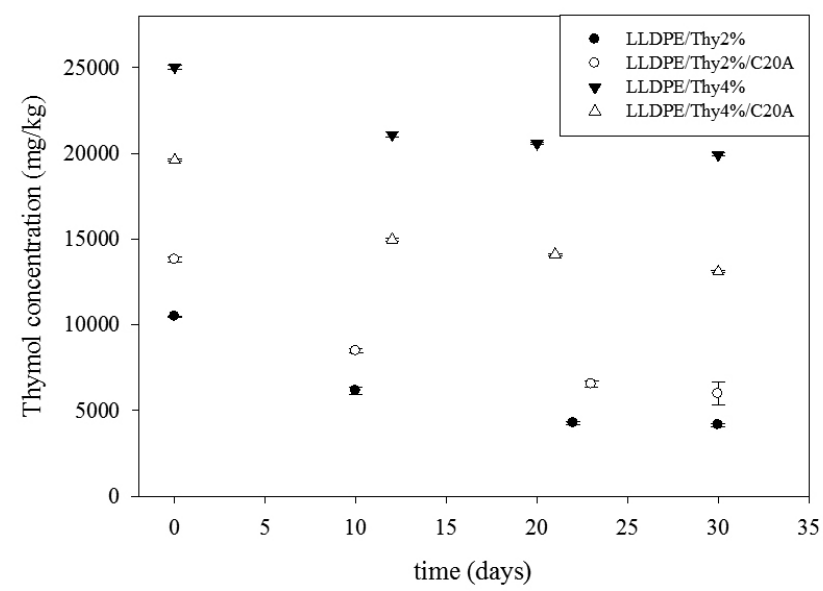
$(\%)$.

Figure 1: Thymol concentration in the LLDPE nanocomposites over time

Extractions of active materials were carried out after one month, and as Table 1 and Figure 1 shows, there were some losses due to thymol volatility and the low compatibility between active agent and polymer matrix. Excepting materials with $4 \%$ thymol, materials with organoclays incorporated presented higher thymol retention into the polymer (62-69\% approximately), probably due to interactions between organoclays and active compound ${ }^{31}$.

\section{Antioxidant activity of materials}

To determine the antioxidant activity, extractions of the developed materials with methanol were conducted and the solutions were measure through DPPH method. Results are exposed in Figure 2 and surprisingly materials with 2 and $4 \%$ wt. $\%$. of thymol presented similar antioxidant capacity, and when organoclays were incorporated antioxidant activity increased. 


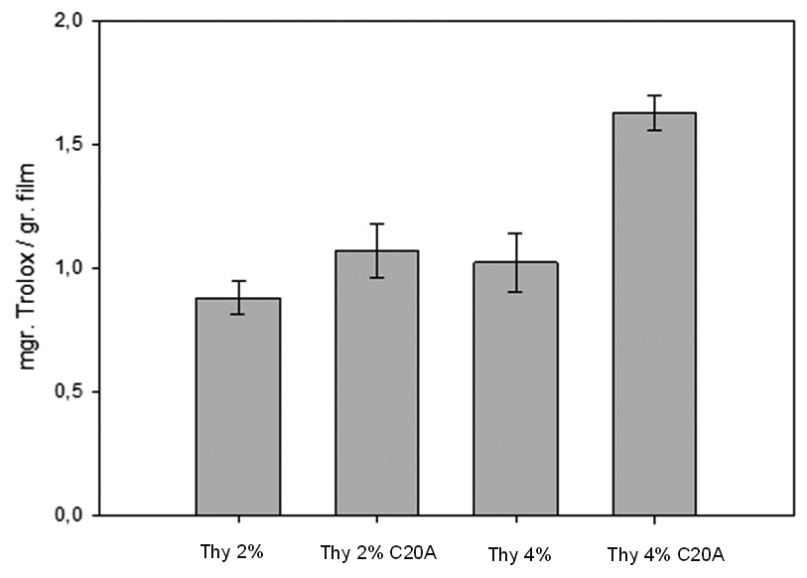

Figure 2: Antioxidant activity of developed materials as Trolox equivalents.

The differences are due to the higher availability of thymol in the samples with organoclays. As shown in previous works, thymol presented higher miscibility to hydrophobic polymers with the presence of organoclays than in neat polymer, enhancing the availability of this antioxidant through longer periods of time because antioxidant is better incorporated into the polymer matrix $^{18,19}$. Losses due to its volatility, that are common when the active compound are incompatible with the polymer and migrates to the film surface, were decreased.

\section{Thermal Characterization}

Thermal analyses of the films were carried out to study the influence of the addition of thymol and modified organoclays on the thermal stability and morphology of the polymer. As thermograms on Figure 3 and values obtained from first derivative in Table 2 show, the addition of the antioxidant improved slightly the thermal stability of the polymer due to the antioxidant character of thymol.

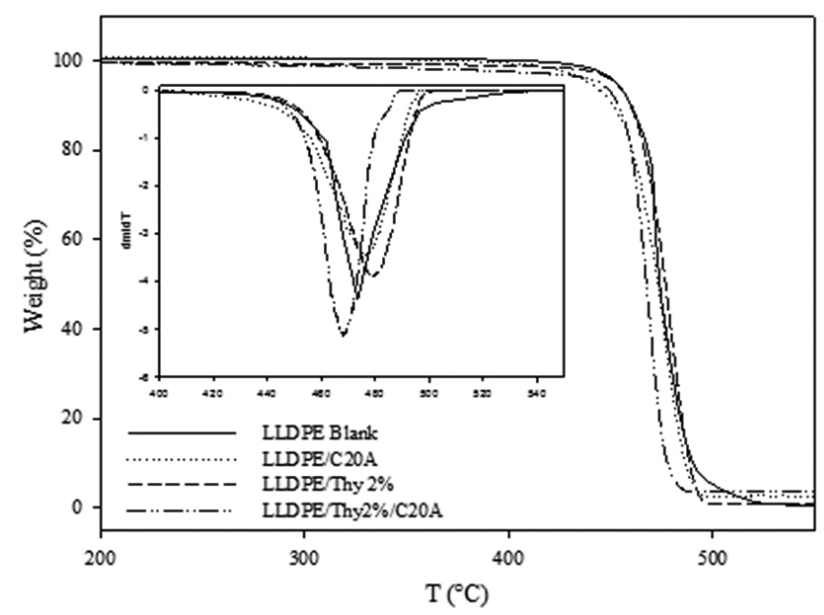

Figure 3: TGA and derivative curves (inset) of LLDPE and LLDPE nanocomposite films developed.

Because of LLDPE degrades with formation and decomposition of hydroperoxides and the propagation and termination steps of the chain reaction are emphasized with the presence of alkyl radicals, thymol, as antioxidant and thereby its radical scavenger character, protected polymer thermal degradation ${ }^{32}$. Nevertheless, when modified organoclays were also incorporated, degradation occurred at lower temperatures because some of thymol incorporated interacted with organoclays hindering its protective character.

On the other hand, DSC analyses were also carried out with the aim of investigating the effects of organoclays addition on the thermal properties of LLDPE nanocomposites. DSC results are usually useful to provide some evidence of miscibility of polymer blends according to physical phenomena such as melting process and crystallization. Table 2 summarizes the significant thermal properties.

Table 2. DSC maximum of melting temperature (Tm), melting enthalpy $(\triangle \mathrm{Hm})$ and LLDPE crystallinity of developed materials.

\begin{tabular}{|l|c|c|c|c|}
\hline \multicolumn{1}{|c|}{ Sample } & $\mathbf{T}_{\mathbf{m}}\left({ }^{\circ} \mathbf{C}\right)$ & $\Delta \mathbf{H}_{\mathrm{m}} \mathbf{c o r r}(\mathbf{J} / \mathbf{g})$ & Crystallinity $(\%)$ & $\mathbf{T}_{\text {de }}\left({ }^{\circ} \mathbf{C}\right)$ \\
\hline LLDPE & 124.78 & 108.0 & 36.78 & 471 \\
\hline LLDPE/C20A & 124.98 & 114.42 & 38.97 & 477 \\
\hline LLDPE/Thy2\% & 124.94 & 100.24 & 34.14 & 480 \\
\hline LLDPE/Thy2\%/C20A & 124.46 & 108.71 & 37.03 & 468 \\
\hline LLDPE/Thy4\% & 125.33 & 85.1 & 28.99 & 476 \\
\hline LLDPE/Thy4\%/C20A & 124.81 & 109.67 & 37.35 & 469 \\
\hline
\end{tabular}

Crystallinity was influenced by thymol concentration due to an increase on amorphous zones that at the same time can favor thymol release on food simulants. Nevertheless, this decrease of crystallinity was lower with the presence of organoclays. In general, melting temperature was not affected by the incorporation of thymol and organoclays, but melting enthalpy and crystallinity shifted to lower values with the incorporation of thymol due to the fact the active compound interrupted crystallization of the polymer chain. The addition of organoclay induced some nucleating effect, improving crystallization process, equilibrating the negative effect of thymol.

\section{$\mathrm{X}$-ray diffraction analysis}

X-ray diffraction technique was used to reveal the kind of interaction between the polymer, active compound and the clay mineral. The degree of intercalation or exfoliation of polymer/clay nanocomposites is known to be affected by the compatibility between the polymer matrix and the type of clay. The higher the increase of the basal spacing in the nanocomposites, the better the intercalation of the polymer inside the clay layers. Figure 4 shows the XRD patterns for C20A and LLDPE nanocomposites with different thymol concentrations.

The XRD pattern of Cloisite $20 \mathrm{~A}$ revealed the diffraction peak at $2 \theta$ equal to $3.34^{\circ}$. The layer distance (d-spacing) of $\mathrm{C} 20 \mathrm{~A}$ was determined using the Bragg's equation and was $2.64 \mathrm{~nm}$.

Figure 4 shows, that once organoclays were incorporated into the films, the diffraction peaks of the clays were shifted to lower angles, correspond to an increase in d-spacing for all nanocomposites. The higher basal spacings of clays in the nanocomposites, as compared to the pristine organoclays, are due to the intercalation of polymer chains inside the clay layers. XRD results are similar to previous works, where in the case of Cloisite 20A, a minor diffraction peak was observed at $2 \theta$ equal to $7.25^{\circ}$, which is caused by the incomplete surface modification of natural Montmorillonite (MMT) when producing Cloisite 20A $(33,34)$. XRD results also indicated a slightly lower degree of intercalation in the nanocomposites with thymol, due probably to the lower compatibility between the hydrophilic character of the clays, and the hydrophobic thymol substance.

The same effect was shown on previous works, where cinnamon and carvacrol were added as antimicrobial agents in cellulose acetate butyrate/ modified motmorillonite (Cloisite20A and Cloisite30B) nanocomposites ${ }^{27}$.

\section{Fourier Transform Infrared Spectroscopy (FTIR)}

Information on the nature of the molecular interactions between thymol and organoclays within the LLDPE matrix was monitored using infrared spectroscopy. The spectrum of LDPE is characterized by typical bands of absorption of polyolefin, which correspond to carbon-carbon and carbonhydrogen bonds. Organoclay presented the characteristic bands of the aluminosilicate minerals. The nanocomposite spectrum presented the presence of bands in the zone of absorption of the silicate groups between $900-1100$ $\mathrm{cm}^{-1}$ confirming the incorporation of the nanoclays in LLDPE matrix (Figure 5). Exactly the bands found were at $460 \mathrm{~cm}^{-1}$ (Si-O-Si bending), $520 \mathrm{~cm}^{-1}$ (Si-OAl bending), $1040 \mathrm{~cm}^{-1}$ (Si-O stretching), and at $1075 \mathrm{~cm}^{-1}$ (-OH bending from absorbed water $)^{27-35}$. 


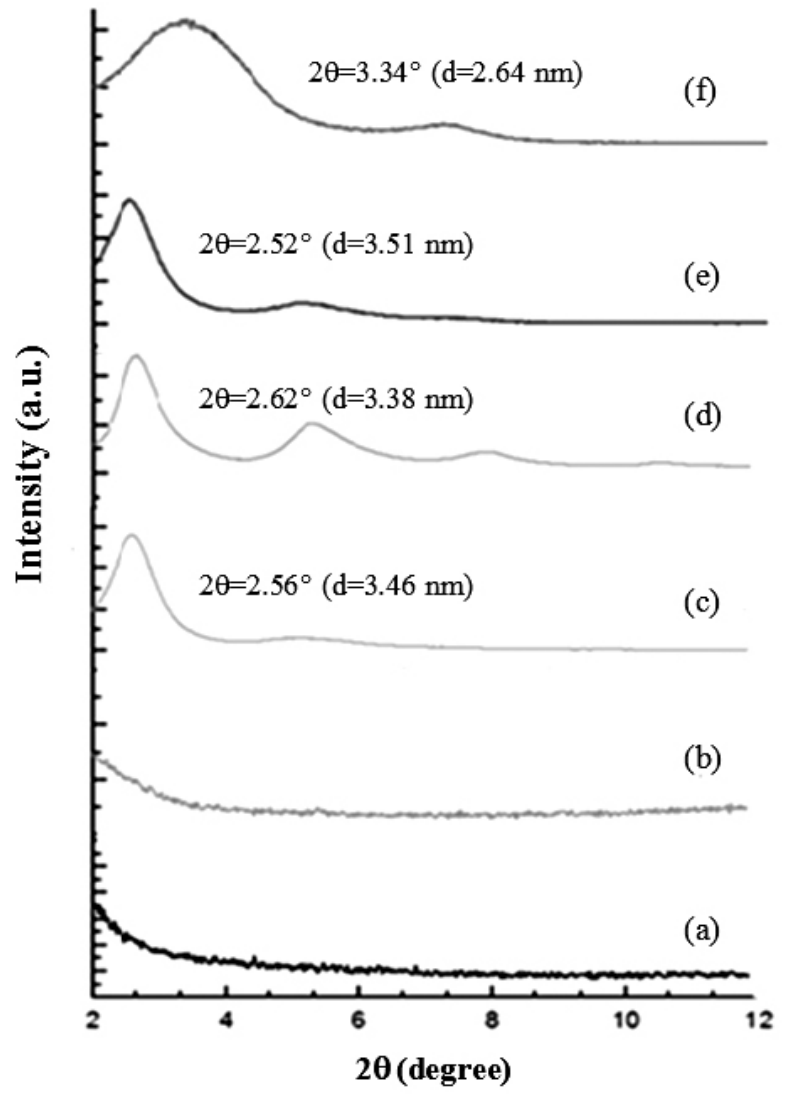

Figure 4: X-ray diffraction patterns of organoclay (Cloisite 20A) and LLDPE nanocomposites films: (a) neat LLDPE, (b) LLDPE/Thy, (c) LLDPE/ Thy $2 \% / C 20 A$, (d) LLDPE/Thy4\%/C20A, (e) LLDPE/C20A, and (f) C20A.

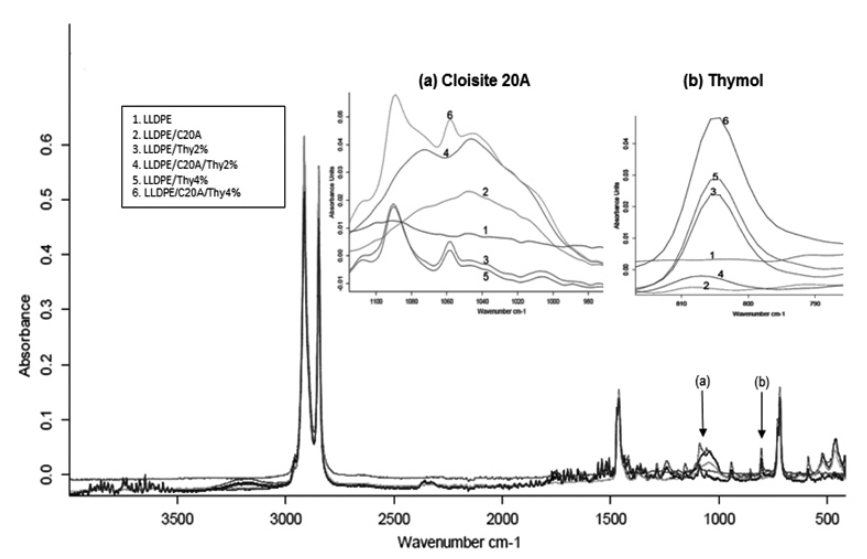

Figure 5: Fourier transform infrared spectra of LLDPE films.

In the case of active materials, it is possible to observe the characteristic bands for thymol, at 730 and $805 \mathrm{~cm}^{-1}$ owing to ring vibrations of aromatic groups $^{36}$. Presence of thymol evidenced by the presence of phenolic groups bands from 3650 to $3200 \mathrm{~cm}^{-1}$, and at $1260-970 \mathrm{~cm}^{-1}$ corresponding to C-O bending. As Figure 5a shows, some displacement of thymol peaks occurred with the presence of organoclay, revealing some interactions between thymol and modified organoclays. Previous works have declared that the nanocomposites presented higher solubility of natural antimicrobials than the neat polymer due to the presence of organoclays ${ }^{18}$. That is an important fact because lower solubility and compatibility of volatile active agents on polymer neat matrix implies high losses of active agent during manufacturing process of active materials, and higher migration of the active compound to the film surface leading to fast losses of active compound during materials shelf life.

\section{Optical properties}

Colour and transparency are important factors to be considered in food packaging since they could influence consumer acceptance and commercial success of a food product. Figure 6 shows the visual aspect of all formulations and Table 3 reports the optical properties of neat LLDPE films and LLDPE nanocomposites.

The presence of organoclays did not affect very much the optical properties of materials, luminosity values were mantained. Though lightness of the films (Hunter L value) did not change appreciably after formation of nanocomposite, the total color difference $(\Delta \mathrm{E})$ of nanocomposite films increased significantly $(\mathrm{p}<0.05)$ compared to that of neat LLDPE film, which was caused by development of slight greenish tint in the LLDPE nanocomposite films.

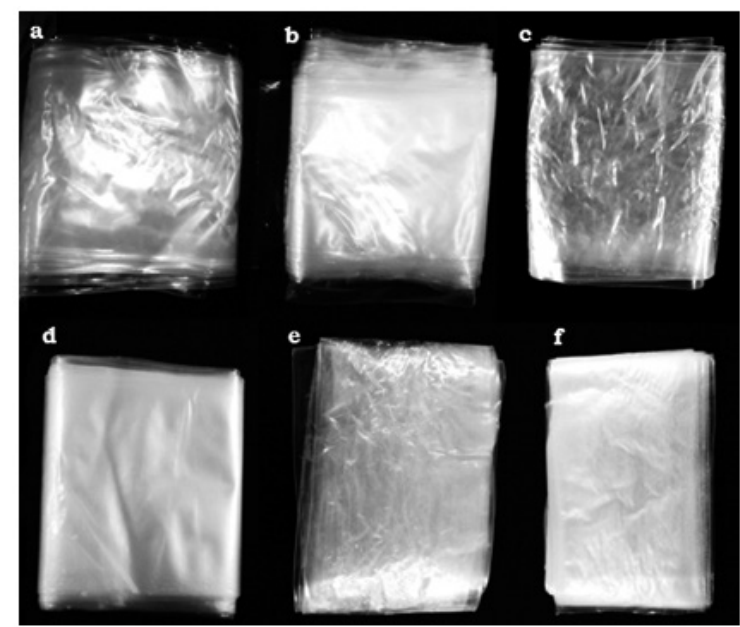

Figure 6: Visual observation of neat LLDPE and nanocomposites films: a) neat LLDPE, b) LLDPE/C2A, c) LLDPE/Thy2\%, d) LLDPE/Thy2\%/C20A, e) LLDPE/Thy4\%, and f) LLDPE/Thy4\%/C20A.

The blend LLDPE/Thy $4 \% / \mathrm{C} 20 \mathrm{~A}$ showed the higher value for $\triangle \mathrm{E}$, as expected, due to the high concentrations of the additives used $(5 \mathrm{wt} \% \mathrm{C} 20 \mathrm{~A}$ and $4 \mathrm{wt} \%$ thymol). The decrease in the optical properties of the LLDPE/clay nanocomposite films in the present study suggests that the clays might not be fully intercalated or exfoliated in the polymer matrix, which was verified in the XRD results.

Table 3. Optical properties of neat LLDPE and LLDPE nanocomposites.

\begin{tabular}{|c|c|c|c|}
\hline Films samples & $\mathbf{L}^{*}$ & $\Delta \mathbf{E}$ & Whitish Index \\
\hline LLDPE & $90.26 \pm 0.57^{\mathrm{a}}$ & $0.0 \pm 0.0^{\mathrm{a}}$ & $89.41 \pm 0.57^{\mathrm{a}}$ \\
\hline LLDPE/C20A & $89.76 \pm 0.33^{\mathrm{b}}$ & $1.23 \pm 0.22^{\mathrm{bc}}$ & $89.27 \pm 0.31^{\mathrm{a}}$ \\
\hline LLDPE/Thy2\% & $89.93 \pm 0.25^{\mathrm{ac}}$ & $1.17 \pm 0.24^{\mathrm{bc}}$ & $89.4 \pm 0.24^{\mathrm{a}}$ \\
\hline LLDPE/Thy2\%/C20A & $89.86 \pm 0.29^{\mathrm{cd}}$ & $0.82 \pm 0.3^{\mathrm{a}}$ & $89.19 \pm 0.28^{\mathrm{a}}$ \\
\hline LLDPE/Thy4\% & $90.77 \pm 0.25^{\mathrm{c}}$ & $1.26 \pm 0.21^{\mathrm{c}}$ & $89.25 \pm 0.28^{\mathrm{a}}$ \\
\hline LLDPE/Thy4\%/C20A & $90.78 \pm 0.43^{\mathrm{b}}$ & $1.82 \pm 0.23^{\mathrm{d}}$ & $89.65 \pm 0.4^{\mathrm{b}}$ \\
\hline
\end{tabular}

Each value is the mean of five replicates with the standard deviation. Some letters for each column are not significantly $(p>0,05)$ different by Fisher's multiples range test.

\section{Scanning Electron Microscopy (SEM)}

Microstructure of LLDPE films was tested with Scanning Electron Microscopy as shown in Figure 7.

As can be observed in the SEM images (see Figure 7a), the upper surface of the net LLDPE film is very soft and smooth. Meanwhile the surfaces of the nanocomposite films developed are different because the presence of particles modifies the surface texture, changing the structure of the material and causing the more imperfect film that is observed ${ }^{22}$. This could be attributed to agglomeration of the nanoparticles, which is best seen in the case of nanocomposites with the highest concentration of active compound (see Figure $7 \mathrm{e})$. 

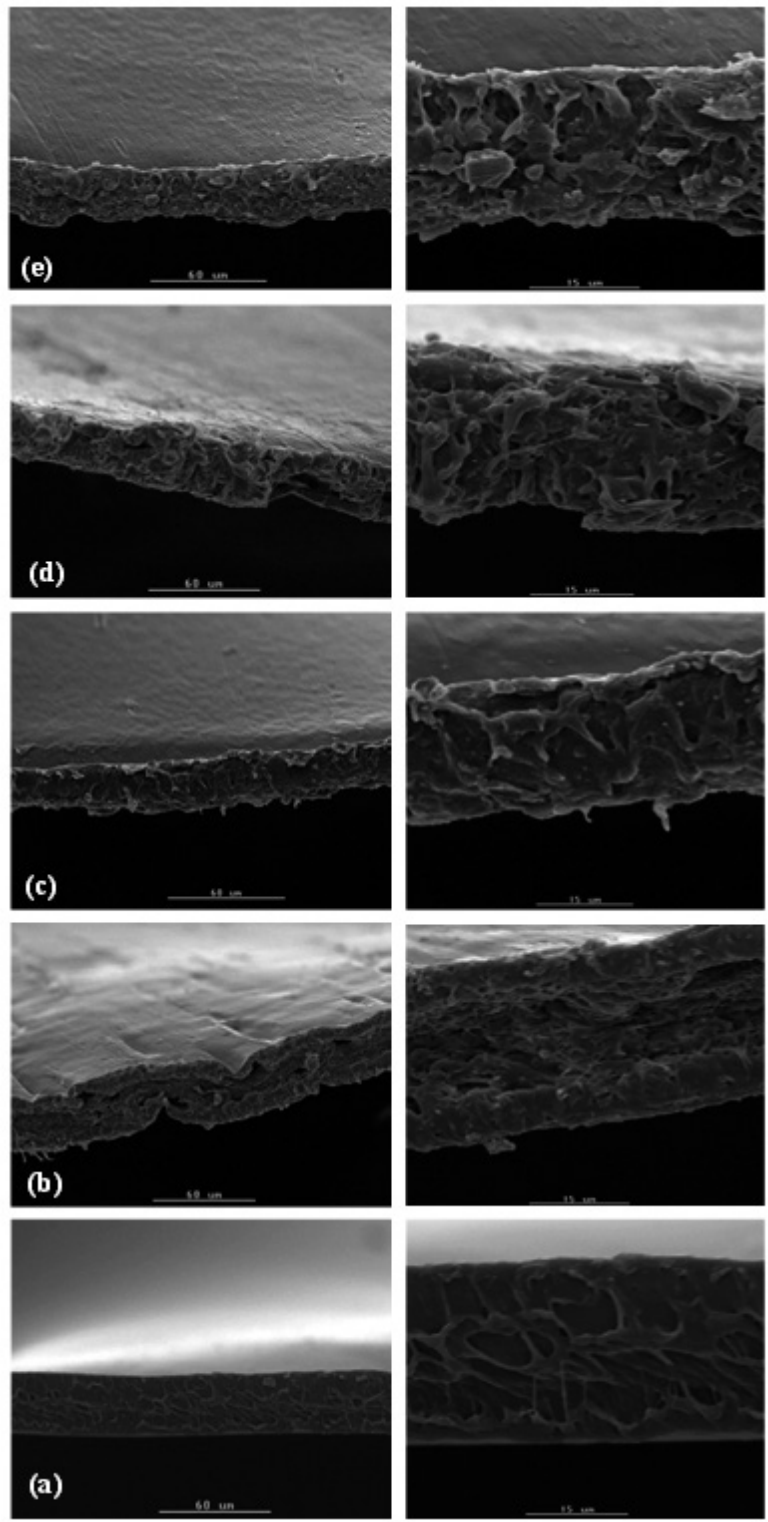

Figure 7: Scanning electronic microscopy analysis of the cross-sections: x500 (left) and x2200 (right) of the different LLDPE films: a) LLDPE, (b) LLDPE/C20A, (c) LLDPE/Thy, (d) LLDPE/Thy2\%/C20A (e) LLDPE/ Thy $4 \% /$ C $20 \mathrm{~A}$.

\section{CONCLUSIONS}

In this study, LLDPE nanocomposites with different thymol concentrations were developed. Extraction procedures revealed final concentrations of active compound in the nanocomposites between $40-80 \%$ of thymol that was initially included in the films formulation. The nanocomposites with 2 and $4 \%$ of thymol presented similar antioxidant capacity, and when organoclays were incorporated materials increased antioxidant activity. XRD results indicated a slightly lower degree of intercalation in the nanocomposites with thymol, due probably to the lower compatibility between the hydrophilic character of the clays, and the hydrophobic thymol substance.

\section{ACKNOWLEDGEMENTS}

The authors thanks to CONICYT (Fondecyt Postdoctoral Project 3130462) and Programa de Financiamiento Basal para Centros Científicos y Tecnológicos de Excelencia (Project FB0807).

\section{REFERENCES}

1. R. Ahvenainen. Novel Food Packaging Techniques. Woodhead publishing limited, Cambridge, England, 2003.

2. G. Bureau, J-L. Multon. Food Packaging Technology, VCH publishers, New York, 1996; pp. 1-367.

3. G.L. Robertson, Food Packaging. Principles and Practices. 2 ed. CRC Taylor \& Francis, Boca Raton, FL., 2006.

4. G. Robertson, State-of-the-art biobased food packaging materials. In E Chiellini (Ed.), Environmentally compatible food packaging, Cambridge, England, Woodhead Publishing Ltd., 2008; pp. 3-28.

5. S.J. Nikkahah, S.A.A. Ramazani, H. Baniasadi, F. Tavakolzadeh, Mater. Des., 30, 2309, (2009).

6. A. López-Rubio, J.M. Lagarón, and M.J. Ocio, Active Polymer Packaging of Non-Meat Food Products, In Kerry J and Butler P, Smart Packaging Technologies, John Wiley \& Sons Ltd., Chichester, England, 2008; p. 340

7. J. Miltz, N. Passy, and C.H. Mannhwim, Trends and applications of active packaging systems, In Ackerman P, Jagerstad M and Ohlsson T, eds. Food and packaging materials - Chemical interaction 162, The Royal Society of Chemistry, 1995.

8. M.L. Rooney. Plastic in Active Packaging, In Rooney ML, ed. Materials and development of plastic packaging, 1995.

9. D. Dainelli, N.Gontard, D. Spyropoulos, E. Zondervan-van den Beuken, P. Tobback, Trends Food Sci. Tech. 19, 103, (2008).

10. N.N. de Kruijf, M. van Beest, R. Rijk, T. Sipiläinen-Malm, L.P. Paseiro, B. De Meulenaer, Food Addit. Contam. 19, 144, (2002).

11. A. López-Rubio, E. Almenar, P. Hernandez-Muñoz, J.M. Lagarón, R. Catalá, and R. Gavara, Food Rev. Int., 20, (2004).

12. J. Kerry, and P. Butler. Smart packaging technologies. John Wiley and Sons Ltd., Chichester, England, 2008.

13. M. Ozdemir, J.D. Floros, Active food packaging technologies, Crit Rev Food Sci Nutr. 44, 185, (2004).

14. P. Suppakul, J. Miltz, K. Sonneveld, and S.W. Bigger, J. Food Sci., 68, $408,(2003)$

15. J.F. Ayala-Zavala, G.A. González-Aguilar, and L. Del-Toro-Sánchez, J. Food Sci., 74, 84, (2009).

16. A. Torres, A. Guarda, N. Moraga, J. Romero, and M.J. Galotto, Eur Food Res Technol. 234, 713, (2012).

17. F. Manzanarez-López, H. Soto-Valdez, R. Auras, and E. Peralta, J. Food Eng., 104, 508, (2011).

18. M.D. Sanchez-Garcia, A. Lopez-Rubio, and J.M. Lagaron, Trends Food Sci. Tech. 21, 528, (2010).

19. M. Ramos, A. Jiménez, M. Peltzer, and M.C. Garrigós, Food Chem. 162, $149,(2014)$.

20. C. Sánchez-Moreno, Food Sci. Technol. Int., 8, 121, (2002).

21. D.A. Pereira de Abreu, P. Paseiro Losada, I. Angulo, J.M. Cruz, Eur. Polym. J. 43, 2229, (2007).

22. S. Zhu, J. Chen, Y. Zuo, H. Li, and Y. Cao, Appl. Clay Sci. 52, 171, (2011).

23. G. Malucelli, S. Ronchetti, N. Lak, A. Priola, N.T. Dintcheva, F.P. La Mantia, Eur. Polym. J. 43, 328, (2007).

24. P. Persico, V. Ambrogi, C. Carfagna, P. Cerruti, I. Ferrocino, and G. Mauriello, Polymer Eng. Sci. 49, 1447, (2009).

25. S-I. Hong, J-W. Rhim, LWT - Food Sci. Technol. 48, 43, (2012).

26. J. Morawiec, A. Pawlak, M. Slouf, A. Galeski, E. Piorkowska, N. Krasnikowa, Eur. Polym. J. 41, 1115, (2005).

27. R.I. Quintero, F. Rodriguez, J. Bruna, A. Guarda, and M.J. Galotto, Packag. Technol. Sci., 26, 249, (2013).

28. B. Zidelkheir, and M. Abdelgoad, J. Therm. Anal. Calorim. 94, 181, (2008).

29. M.J. Galotto, X. Valenzuela, F. Rodríguez, J. Bruna, and A. Guarda, Packag. Technol. Sci., 25, 363, (2012).

30. P. Suppakul, K. Sonneveld, S.W. Bigger, and J. Miltz, J. Food Eng. 105, 270, (2011).

31. L.A. Rupika, Development and Evaluation of LDPE-based antimicrobial food packaging films. Proceeding 22nd IAPRI Sympossium. London 2225 May, (2010).

32. L. Qiu, W. Chen, and B. Qu, Polymer 47, 922, (2006).

33. J-W. Rhim, S-B. Lee, and S-I. Hong, J. Food Sci., 76, 40, (2011).

34. H.M. Park, X. Li, C.Z. Jin, C.Y. Park, W.J. Cho, and C.S. Ha, Macromol Mater. Eng. 287, 553, (2002).

35. S. Tzavalas, and V.G. Gregoriou, Vib. Spectrosc, 51, 39, (2009).

36. H. Schulz, B. Schrader., R. Quilitzsch, S. Pfeffer, and H. Kruger, J. Agric. Food. Chem. 51, 2475, (2003). 